\title{
Emergence and preservation of a chronically sick building
}

\author{
Åke Thörn
}

\begin{abstract}
Study objective-To investigate the merits of case studies as complementary methodological approaches in the study of the sick building syndrome.

Setting and participants-A Swedish office building with longstanding health problems, and its inhabitants.

Design-This paper is a case study based both on historical and present, quantitative as well as qualitative, documentary material, produced over the years by distinct parties, and on semi-structured interviews.

Results-Long drawn conflictive processes within the building were identified. It was revealed that the organisation for dealing with environmental problems was split, and ineffective with poor patterns of communication. It was suggested that this generated a situation of chronic stress leading to the persistence of symptoms. Conclusions-By their capacity to identify internal processes within building contexts, case study methodology can contribute to a better understanding and management of sick building syndrome. The results of this study suggest that psychosocial factors, among them organisational structures and communication patterns, should be given close attention. (F Epidemiol Community Health 2000;54:552-556)
\end{abstract}

Karolinska Institutet, Department of Public Health Sciences, Division of Social Medicine, Stockholm, Sweden and

Yrkesmedicinska Enheten, Bodens Sjukhus, Boden, Sweden

Correspondence to: Dr Thörn, Yrkesmedicinska Enheten, Sunderby Sjukhus, 97180 Luleå, Sweden (ake.thorn@nll.se)

Accepted for publication 22 February 2000 toms and exposure, and the resulting difficulties in defining either disease or cause. ${ }^{9}$ A need for the application of other research methods than traditional epidemiological ones has therefore been pointed out. ${ }^{8-10}$ Several authors have argued for the use of qualitative methods in medical research ${ }^{11-13}$ as a complement to quantitative ones. Case studies are qualitative study approaches, which entail the detailed examination of one subject (for example, the classic clinical patient case study), one setting or one particular event. They focus on contexts attempting to understand how interactions between many inter-related factors might explain observed events. ${ }^{13}$ Against this background, the aim of this study is to examine whether a case study approach can contribute to the understanding of the emergence and persistence of sick building syndromes.

\section{Methods}

CASE SELECTION AND SOURCES OF INFORMATION For the study, buildings with long problem histories were wanted. The Labour Inspectorate identified the only two office buildings in its surveillance district with non-specific health problems having been reported all since the 1980s. Using multiple sources of information, (table 1) both were studied, and one is presented here.

THE CASE BUILDING

Located in a small town, the building was owned and operated by a private property management company. Its tenant (contract holder) was a municipal administrative unit, which in turn rented it to three other municipal office units, concerned with different public services. It was the tenant, who served as the official interface between the occupants and the building owner. The three storey building consisted of two adjacent bodies, constructed in 1984-1985. Its main structure was made of concrete with external brick walls. The interior consisted of plaster discs covered with wallpaper. The flooring had been changed over the years, and consisted since 1990 of linoleum

Table 1 Sources of information

\begin{tabular}{ll}
\hline Sources with basically quantitative information & Sources with basically qualitative information \\
\hline $\begin{array}{l}\text { Cross sectional prevalence studies done by the local OSH } \\
\text { Construction drawings }\end{array}$ & $\begin{array}{l}\text { Minutes, notes, appeals and proclamations from meetings held by the personnel } \\
\text { Minutes from municipal political boards concerned with planning, construction } \\
\text { and environment }\end{array}$ \\
$\begin{array}{l}\text { Investigation reports regarding the office building and its physical environment, } \\
\text { performed by the proprietor and his consultants, the local OSH and the } \\
\text { municipal Technical Office }\end{array}$ & $\begin{array}{l}\text { Letters exchanged between employer, employees and proprietor } \\
\text { Articles from local news media } \\
\text { Interviews with a selection of persons who worked in the building, or had other } \\
\text { relations to it }\end{array}$ \\
\hline
\end{tabular}




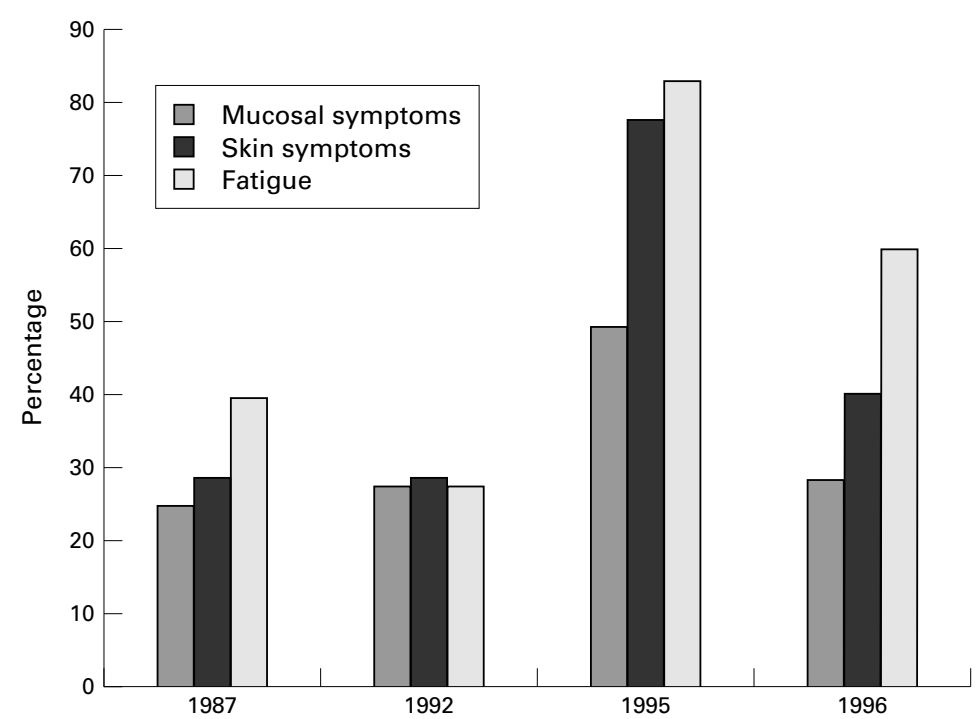

Figure 1 Prevalence (\%) of SBS symptoms among the occupants of the building 1987-1996. sources (table 1) and the interviews were done by one person. Upon completion of the study, each respondent was given a copy of the draft report. Comments were solicited and integrated into the final report. The respondents' permission to publish the report was obtained.

\section{Results}

SYMPTOM DEVELOPMENT

Symptoms were reported soon after moving into the building. Over time, their prevalence increased gradually. From 1987 and continuing on through 1996, the OSH repeatedly performed prevalence studies among the personnel. ${ }^{15}$ The encountered prevalence (fig 1) was considered high.

Workplace investigations and remedial actions Between 1987-1996, the building was investigated by the owner's different consultants, the tenant's (contract holder's) technicians, and the occupant units themselves through the $\mathrm{OSH}$. No coordination occurred among the investigators nor those mandating the investigations. Reports were often incomplete and rarely shared. Therefore, it is impossible to get a comprehensive picture of their scope, findings and conclusions.

Some defects in the ventilation system were identified, leading to the removal of the system's rotating heat exchange device in 1987. In 1988, the office was evacuated while the ventilation was rebuilt. The inner flooring of the corridors was changed, including the removal of glue and putty. Despite this, symptoms continued. In 1989, new consultants analysed samples of putty and glue from the floor without finding anything abnormal. Without quantitative specifications, they reported the air concentrations of volatile organic compounds (VOC) to be "moderately increased" in some rooms, and "considerably increased" below a few floor mats. The relative humidity $(\mathrm{RH})$ in the concrete below these mats ranged between $66 \%$ and $72 \%$. Based on this, the consultants deduced that the concrete foundation formerly had been sufficiently wet to lead to emissions of gases from substances in the floor mats: "the symptoms might be related to the decomposition of the softening agents and the glue in and under the floor mats. Such decomposition is related both to the type of mat and to the humidity in the concrete foundation. It is impossible to estimate the exact level of $\mathrm{RH}$ in the concrete foundation at the time the mats were glued. It is, however, likely that the moisture content then was a lot higher than it is now."

This conclusion led to the replacement in 1989-1990 of the original PVC mats with non-glued linoleum mats in all rooms. Because of continued symptoms, the consultants repeated their 1989 investigation again in 1995this time without being able to deduce any causative hypothesis of the ongoing problems: "the concrete foundation has dried. VOC is normal. The pollution from decomposed components in mats which in 1989 together with defects in the ventilation were considered the cause of the SBS-symptoms, seems to have 
disappeared." No remedial recommendations could be made. Despite this, the building was evacuated, and the ventilation system was again re-constructed without the prior demonstration of malfunctioning. Once reoccupied, symptoms were again reported (fig 1).

News media coverage

Dominated by three themes, 18 articles concerning the office appeared in the two regional newspapers between 1987 and 1996:

(1) Descriptions of the symptoms and possible causes, often presented as poisonous chemical emissions.

(2) Discussions of the high costs of the repeated remedial measures. This appeared towards the end of the 10 year period, and was put in contrast with the economic crisis the employer then found himself in. In one of these articles, the manager of the tenant unit ("contract holder"), even proposed "reparation can be avoided, and money saved for the employer, if I and my personnel switch offices with the three occupant units".

(3) The third theme dealt with trust and credibility. At first, the personnel's fears of not being believed were expressed: "so much has been done, and still we have symptoms. The general public probably does not believe us when we complain of vertigo and feeling bad in general after work-day, says an employee who wants to be anonymous." Later, a distrust in the property company and its experts was expressed: "the three occupant units refuse to move back to their offices. They do not trust the reassurance given by the property company that the building will be healthy again. The consultants hired are thought to be biased."

\section{Other written sources}

In a correspondence between the property company and the management of the occupant units, the former first claimed that personnel working in the building were sabotaging the ventilation system. Later it claimed that its maintenance personnel were harassed by the personnel in the office, and that therefore "we have now reached the limit! Aren't our efforts worth anything at all?"

The minutes from relevant municipal political boards repeatedly stated that health problems existed in the building. One of these minutes also expressed the demand for immediate action because of strong fears for future incapacitating health problems.

\section{The interviews}

The interviews revealed a long history of unresolved health problems despite numerous remedial measures over the years. Related to this, there emerged five themes, illustrated by the following quotations:

\section{(1) Conflict}

"we were angry with the internal processes, which have been extremely slow, going back and forth between different units"

"we all had different interests to look after, there were many reasons for conflicts, hostility, and, say, territorial fights" "but there was antagonism between different parties; reactions led to drastic counter reactions; clumsy answers demonstrated a lack of understanding, one thing led to another"

(2) Credibility/trust

"all different theories, we moved in and out, and back and forth and finally you don't believe anything"

"They have done something all the time, changed fans, torn floors up, something here, something there, we've had questionnaires over and over again, but nothing changed, and finally, you asked yourself, do they really do anything?"

(3) Economy

"I think many of the experts who have been here, well, they were just interested in money, they just wanted to sell a concept"

"I think it is money that governs them, it is like they look at the costs, and then say, let's try that, if it works, then fine."

\section{(4) Gender}

"they have been dribbling for years, and done this and that, but basically all the time they have thought it was female nonsense"

"They say more or less openly that this is women talk, for instance, they proposed that we should change offices with them, that we should move to their office and they to ours, so they could demonstrate what supermen they are."

\section{(5) Systematic}

"we would have liked a more systematic approach to the work, but with all different actors, we didn't even have the access to the consultants' results"

"they have measured and measured, and said this and that, but you never really know what they said, and it was as if they never saw to the totality, to the building as such"

The recurrent patterns underlying the themes, were phrased as if they were determinants in an hierarchical order with economy and gender in the first level. Thus, it seemed as if economic and gender attitudes were considered to determine the degree of conflicts and credibility/trust within the building, as well as the extent to which systematic investigative procedures were done.

\section{Epilogue}

In 1996, the union filed a complaint with the Labour Inspectorate. The employer was formally notified that if he did not identify and remedy the presumed building related causes of the non-specific health problems, the Inspectorate would consider prohibiting the building's use. The employer cancelled the rental contract, and the building was abandoned.

\section{Discussion}

\section{THEORETICAL PERSPECTIVES}

Most theories regarding SBS aetiology are biomedical, postulating unknown specific factors as being responsible for symptoms along distinct pathophysiological pathways. ${ }^{16}{ }^{17}$ The underlying hypotheses appear to be that chemical emissions from building materials cause the symptoms. However, because of the 


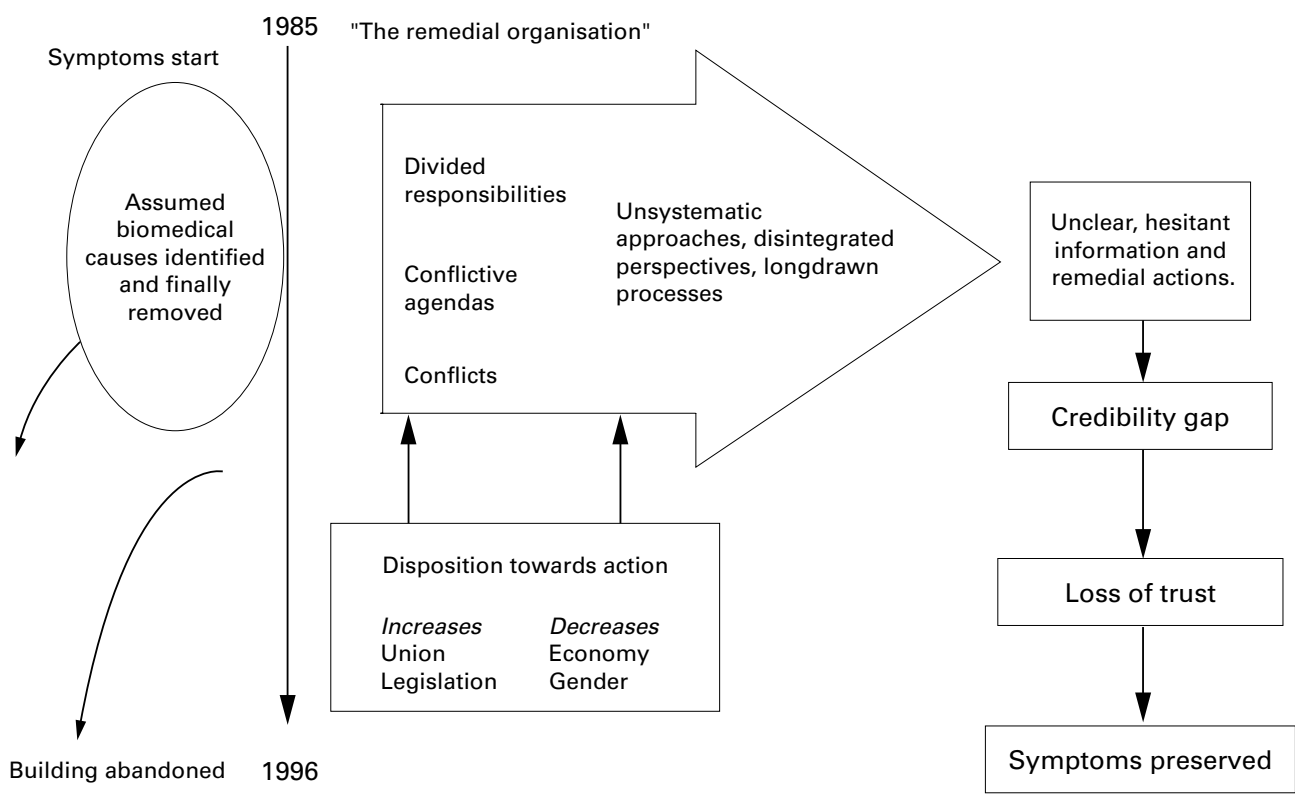

Figure 2 Influence of structural and other factors over the generation of chronic, non-specific symptoms in the building.

large number of potential causative, specific agents, the difficulty in characterising exposure, along with the multitude of possible symptoms, such hypotheses presently are almost impossible to test. ${ }^{18}$ Still, research demonstrating correlations between SBS symptoms and ventilation parameters and/or damp buildings give $^{419}$ some indirect support to the assumption that SBS might be attributable to chemical exposures. This was the rational basis for the remedial actions in the case building. Within such a biomedical perspective, the persistence of symptoms after renovation often is interpreted as being attributable to sensitisation, with reactions theoretically attributed to even minor exposures to hypothesised, unknown noxious factors. On the other hand, sick buildings seem to harbour complex interactions between physical environments and psychosocial processes. ${ }^{10}$ It has been pointed out that failure to tackle factors such as job satisfaction and work stress can complicate, even compromise attempts to resolve indoor air complaints. ${ }^{20}$ Several studies suggest a strong part played by psychosocial factors in the development of SBS. ${ }^{521}$ This is why it has been proposed that bio-psycho-social perspectives and approaches should be used in its study and analysis. ${ }^{22}$ Similarly, it has been suggested that it might be fruitful to view environmentally related syndromes from the multi-faceted perspectives of systems theory. ${ }^{7}$

THE CASE OFFICE IN A BIO-PSYCHO-SOCIAL PERSPECTIVE: A MODEL

In the presented office history, there were two main phases. The first lasted from the start of the problems in 1986 up to the end of 1989 . During this phase, a biomedical causative hypothesis was deduced and consequent actions were taken. Local news articles were dominated by themes suggesting that various supposed physicochemical causes were responsible for the problems. At that time, such a hypothesis seemed to be a reasonably credible way to explain the reported health problems. However, also in the first phase, information from news reports, minutes of meetings and correspondence indicated the existence of conflicts between the different parties concerned with the health problems. The second phase, beginning in 1990, was characterised by the persistence of symptoms despite the presumably biomedically evidence-based remedial actions, based on the proposals of the consultants' 1989 report. During this phase, various minor and major actions were taken, all without any demonstrated prior faults in the building. No deductions as to possible biomedical causes could be made. In the local newspapers, articles appeared suggesting an atmosphere of distrust between the concerned parties. The interviews support and deepen this scenario, further suggesting that economic and gender perspectives might influence how building related health problems were approached and managed.

It seems, then, that while a sole biomedical perspective offered a moderately plausible approach to understanding the first phase, it failed to do so in the second. To credibly explain both phases, a combined bio-psychosocial perspective on the office history seems more feasible. The health problems were handled by a "remedial organisation" that consisted of five independent units (owner, tenant, three independent occupant units) each with different and unclear responsibilities. There were hostile interrelationships and ineffective communication between these units, a lack of integrated and comprehensive perspectives, and an absence of systematic work procedures.

Some societal factors probably increased the disposition of this "remedial organisation" towards actions; for example, legislation. Other factors, such as costs and gender, seem to have diminished this disposition (see model in fig 2).

In the end, the efforts undertaken by the complicated "remedial organisation" appear as 
lengthy, ineffective, hesitant, characterised by poor communication, ultimately depriving these efforts of any real credibility. Against this background, the persistence of symptoms after 1989 can be seen as resulting from a chronic state of stress provoked by ever more complicated psychosocial dynamics within an inadequate organisation, leading to a climate of despair. The links between the symptoms and the psychosocial processes could be various. ${ }^{5}$ The processes may act directly as stressors, causing symptoms through psychophysiological mechanisms. Furthermore, they may render the individual more sensitive to normally tolerated physical and chemical factors in the environment.

VALIDITY AND GENERALISABILITY

The selection of the case building and of the interviewees were made as non-random, purposeful samples. ${ }^{23}$ Therefore, the results cannot be generalised on a statistical basis. However, given sufficient validity, they can be generalised on an analytical one. ${ }^{24}$ According to its definition, SBS is determined by the occurrence of the increased prevalence of nonspecific symptoms in certain buildings. ${ }^{1} \mathrm{Be}-$ cause of the widespread occurrence of these symptoms (in the general population such symptoms are present in frequencies ranging from $20 \%-50 \%,{ }^{9}$ and in offices without health problems from $7 \%-54 \%{ }^{25}$ ), this central diagnostic assumption cannot be proved or disproved objectively. Actually, this means that the validity of the concept SBS cannot be ascertained either in quantitative or in qualitative investigations by other means than a sort of attribution. In the case office, the symptoms were attributed to the building by its users, by the media and by the Labour Inspectorate. For all practical purposes, at the time of its closure, the office with its inhabitants suffered from a chronic SBS at least in the sense that the very concept was well established by attribution. The central issue for this study, however, was the identification of possible structures and developmental processes leading to SBS chronicity. The validity of the proposed structures and processes can only be evaluated based on criteria that fit qualitative research. ${ }^{142326} \mathrm{Ap}$ plying these, it seems as if the study were sufficiently consistent, transparent and credible to permit the following general conclusions. Case study design can facilitate the identification of complicated processes, including conflicting agendas between concerned parties within buildings. Such processes could be equally responsible for the development of chronic states of SBS as could non-identified biomedically deduced specific agents. The addition of psychosocial dimensions to the commonly used biomedical analytical perspectives renders development towards chronicity more understandable, suggesting that it is insufficient to just remove deduced, biomedical causes. Psychosocial factors, not least organisational structures and communication patterns, should be given the same attention as physicochemical exposures.
KEY POINTS

- Epidemiology alone is insufficient in the study of non-specific, environmentally attributed health problems such as the sick building syndrome

- By offering deeper perspectives, case study methodology is a valuable complementary approach in the study of such areas.

- In the practical dealing with sick building syndromes, there is a need for the application of integrated psychosocial and biomedical perspectives.

Conflicts of interest: none.

1 World Health Organization (WHO). Indoor air pollutants: exposure and health effects. EURO Reports and Studies, no 78. Copenhagen: WHO, 1983.

2 Welch LS. Severity of health effects associated with building-related illness. Environ Health Perspect 1991;95: $67-9$.

3 Apter A, Bracker A, Hodgson M, et al. Overview Epidemiology of the sick building syndrome. $\mathcal{F}$ Allergy Clin Immunol 1994;94 (suppl 2 pt 2):277-88.

4 Hodgson MJ. The sick building syndrome. Occup Med 1995;10:167-75.

5 Eriksson N. The psychosocial work environment and illness among office workers. [Dissertation]. University of Umeå: among office workers. [Dissertation

6 Norbäck D, Michel I, Widström J. Indoor air quality and personal factors related to the sick building syndrome. Scand $\mathcal{F}$ Work Environ Health 1990;16:121-8.

7 Ford CV. Somatization and fashionable diagnosis: illness as a way of life. Scand $\mathcal{F}$ Work Environ Health 1997;23 (suppl 3):7-16.

8 Spurgeon A, Gompertz D, Harrington JM. Modifiers of non-specific symptoms in occupational and environmental syndromes. Occup Environ Med 1996;53:361-6.

9 Spurgeon A, Gompertz D, Harrington JM. Non-specific symptoms in response to hazard exposure in the workplace. f Psychosom Res 1997;43:43-9.

10 Crawford JO, Bolas SM. Sick building syndrome, work factors and occupational stress. Scand $\mathcal{F}$ Work Environ Health 1996;22:243-50.

11 Scheff TJ, Starrin B. Qualitative research in the health sciences. Eur F Public Hlth 1997;7:355-6.

12 Jones R. Why do qualitative research? BMf 1995;311:2.

13 Holman HR. Qualitative inquiry in medical research. $\mathscr{f}$ Clin Epidemiol 1993;46:29-36.

14 Elder NC, Miller WL. Reading and evaluating qualitative research studies. F Fam Pract 1995;41:279-85.

5 Andersson K, Fagerlund I, Stridh G, et al. The MMquestionnaires: a tool when solving indoor climate problems. Orebro: Department of Occupational and Environmental Medicine, Örebro Medical Center Hospital, 1993.

16 Berglund B, Lindvall T. Sensory criteria for health buildings. Indoor Air 90. Plenary lectures. V. Ottawa: Canada Mortgage and Housing Corporation, 1990:65-79.

17 Meggs WJ. Neurogenic switching: A hypothesis for a mechanism for shifting the site of inflammation in allergy and anism for shifting the site of inflammation in allergy and
chemical sensitivity. Environ Health Perspect 1995;103:546.

18 Menzies B, Bourbeau J. Building-related illnesses. $N$ Engl f Med 1997;337:1524-31.

19 Stenberg B. Office illness. The worker, the work and the workplace. [Dissertation]. Umeå: University of Umeå, Department of Epidemiology and Public Health, 1994

20 Redlich CA, Sparer J, Cullen MR. Sick-building syndrome. Lancet 1997;349:1013-16.

21 Bachmann MO, Myers JE. Influences on sick building syndrome symptoms in three buildings. Soc Sci Med 1995;40: $245-51$

22 Ooi PL, Goh KT, Phoon MH, et al. Epidemiology of sick building syndrome and its associated risk factors in Singapore. Occup Environ Med 1998;55:188-93.

23 Britten N, Jones R, Murphy E, et al. Qualitative research methods in general practice and primary care. Fam Pract 1995;12:104-14.

24 Yin RK. Case study research. Design and methods. Applied social research series. Vol 5. Beverly Hills: Sage Publications, 1987.

25 Nelson NA, Kaufman JD, Burt J, et al. Health symptoms and the work environment in four nonproblem United States office buildings. Scand $\mathcal{F}$ Work Environ Health 1995; 21:51-9.

26 Hamberg K, Johansson E, Lindgren G, et al. Scientific rigour in qualitative research-examples from a study of women's health in family practice. Fam Pract 1994;11:17681 . 